\title{
Del Wassermann al VDRL en el antiguo Instituto Bacteriológico de Chile
}

\author{
Walter Ledermann
}

\section{Since Wassermann to VDRL in the ancient Bacteriological Institute of Chile}

The author remembers, sometimes in a very personal and colloquial way, the successive adoption by the ancient Bacteriological Institute of Chile of different nontreponemal tests for the serological diagnosis of syphilis: Wassermann, Kahn and VDRL. The outstanding figures of some agents of those changes, like Rudolf Kraus, Eduardo Dussert and Reuben Kahn, are recreated in the words of first hand eyewitness.

Key words: Wassermann, Kahn, Kraus, Dussert, Bacteriological Institute of Chile.

Palabras clave: Wassermann, Kahn, Kraus, Dussert, Instituto Bacteriológico de Chile.
Hospital Luis Calvo Mackenna, Santiago.

Recibido: 4 de agosto de 2014

Correspondencia a:

Walter Ledermann

oncemayor@gmail.com
$\mathrm{N}$ os perdonarán nuestros lectores cierto carácter coloquial, pero gran parte de este artículo se basa en vivencias personales, en una pretensión, no sabemos si justificada, de rescatar del olvido algunos hechos que pertenecen a la pequeña historia de la medicina en Chile, ocurridos en el antiguo Instituto Bacteriológico, hoy Instituto de Salud Pública, donde trabajamos por diecisiete años.

Descubierto el Treponema pallidum como agente causal de la sífilis, varios bacteriólogos pensaron que sería fácil utilizar esta bacteria en la elaboración tanto vacunas como antígenos para reacciones serológicas de diagnóstico, pero el tenue bacilo ni se teñía ni se cultivaba con las técnicas habituales, dificultades que persisten en la actualidad, aunque Reiter haya obtenido una cepa capaz de crecer en un medio enriquecido, de engorrosa preparación y fácil contaminación, que no ha resultado muy práctico.

La primera solución al problema la aportaron en 1906 los alemanes Wassermann, Neisser y Bruck del Instituto Robert Koch, al utilizar extractos de hígado de fetos sifilíticos como antígenos para una prueba de fijación del complemento, dando origen a la llamada reacción de Wassermann ${ }^{1}$. Como en 1901 los franceses Bordet y Gengou habían desarrollado el método de fijación del complemento para otras bacterias, se apropiaron del test del alemán y empezaron a llamarlo "Bordet-GengouWassermann" o, más simple, "Bordet-Wassermann", absurda pretensión que sólo prosperó en Francia.

La reacción de Wassermann sería mejorada ya al año siguiente por Marie y Levaditi quienes descubrieron identidad antigénica entre el treponema y varios extractos alcohólicos de órganos normales, entre ellos la cardiolipina del miocardio de buey, tras lo cual, comprendiendo que el antígeno no era treponémico, describieron varios productos artificiales cumpliendo la misma función anti- génica, como colesterol, lecitina o glicocolato de sodio ${ }^{2}$.

Como había más bueyes disponibles en el matadero que abortos sifilíticos en los hospitales, el Wassermann se facilitó enormemente y se divulgó por todo el mundo. Así, el antígeno habría comenzado a elaborarse en pequeña escala en Chile alrededor de 1925 en el Instituto de Higiene, aunque con anterioridad podía importarse ocasionalmente el test desde el Instituto Pasteur de Paris, según se jactaba Eduardo Dussert, en uno de sus habituales arranques francófilos.

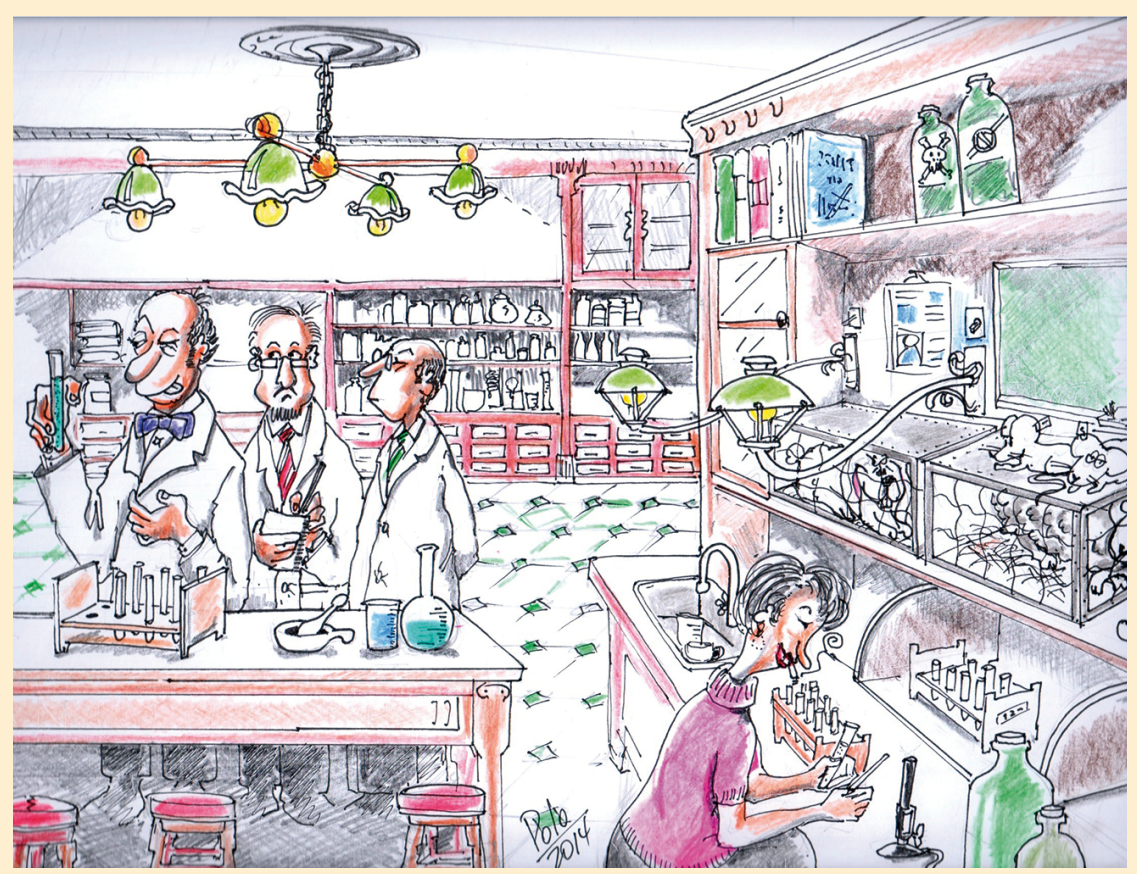


El fundamento de la reacción era el consumo del complemento, que demostraba indirectamente la presencia de anticuerpos en el suero del paciente. A este suero se le eliminaba su propio complemento por calentamiento a $56^{\circ} \mathrm{C}$ durante media hora, elemento que era luego aportado en concentración definida por suero fresco de conejo, agregándose al tubo el antígeno cardiolipina y un sistema hemolítico de glóbulos rojos de cordero y sus anticuerpos hemolíticos. Un tubo de control llevaba sólo este sistema hemolítico, para demostrar que funcionaba y se producía hemólisis. Ahora bien, si en el tubo de reacción había anticuerpos contra el treponema -y, por tanto, contra la cardiolipina- se producía la reacción antígeno-anticuerpo, con consumo (desviación) del complemento de conejo y ausencia de hemólisis; y si, por el contrario, no había anticuerpos en el suero del paciente, no había reacción con la cardiolipina y el complemento ayudaba a lisar los glóbulos de cordero. Entonces, la reacción de Wassermann sin hemólisis era positiva, y con hemólisis era negativa. En la medida que había más anticuerpos, mayor era el consumo de complemento y menor la hemólisis, expresándose la intensidad de la reacción, a ojo de buen cubero, en cruces que iban de 4 a 1 .

Así descrita, parece fácil, pero es preciso imaginarse un laboratorio realizando ochenta o más Wassermann diarias, dada la alta frecuencia de la sífilis, para comprender lo tediosa y demandadora de tiempo que resultaba, así como lo difícil para cualquier hospital obtener glóbulos rojos de cordero y suero fresco de conejo.

El lenguaje popular pronto incorporó las cruces del Wassermann y algunas empresas exigían a quienes postulaban a un empleo no tener cruces en la sangre, cosa que no debe asombrarnos, pues a poco de aparecer el SIDA se empezó a hablar de discriminar a los trabajadores que no presentaran un examen negativo. No nos consta si ello llegó a hacerse efectivo, pues los médicos dotaron a la enfermedad desde su aparición de una connotación de tabú, secreta, misteriosa y hasta prohibida, de tal manera que hasta ahora no se puede hacer el examen de VIH a un paciente hospitalizado sin su consentimiento explícito. Lo que sí nos consta es que en 1935 se exigía el papel de Sanidad o de limpieza para otorgar o denegar trabajo, por temor al tifus exantemático, aunque la enfermedad ya en 1918 se consideraba erradicada del país ${ }^{3}$. En una injustamente olvidada novela criolla de Romanangel, al protagonista se le pide bañarse para conseguir el famoso certificado, a causa del ensantemático, y como éste demora mucho en tomar su heroica resolución, termina por perder la oportunidad y pregunta, desolado, al potencial empleador, dando así término a la obra:

- ¿Qué ahora bañao y sin pega? ${ }^{4}$.

Volviendo a la historia chilena de las reacciones serológicas para el diagnóstico de la sífilis, ella nace con el mencionado Instituto de Higiene, fundado en 1892, cerrado en 1924 y refundado en 1925. Al transformarse éste en 1929 en el Instituto Bacteriológico de Chile (IBCh), su primer director, el Herr Professor austriaco Rudolf Kraus, encarga a Eduardo Dussert la labor de implementar la fabricación y distribución del antígeno de Wassermann, así como la estandarización de la técnica y la evaluación de la entonces novedosa modificación hecha por Kahn.

-El alemán me dijo- nos contó una vez el Profesor Dussert en un raro momento de locuacidad - que toda la sifilis, comprendiendo su patología, sus etapas, su diagnóstico y su tratamiento, era un kaos. Así, con ká alemana, pues cuando Kraus se entusiasmaba con algo olvidaba el castellano, que hablaba, por otra parte, particularmente bien. Y me encargó poner orden, porque Kahn había publicado su artículo en 1923, y ya en 1930 algunos pretendian usarlo en Chile como la gran novedad. Yo venía llegando del congreso de Montevideo, entusiasmado, como todos los participantes, con la nueva reacción.

El “alemán” sabía del tema, había conocido personalmente a Wassermann, trabajado y fundado con él la Asociación Libre para Microbiología, para terminar escribiendo su obituario ${ }^{5}$. Según Dussert, Kraus le habría contado que Wassermann "no era un dilettante de la ciencia, como se lo ha difamado, sino un gran trabajador del laboratorio, a veces muy sarcástico, aunque bueno en el fondo; físicamente pequeño pero bien hecho, siempre muy elegante, tratando de combinar su vestuario con sus ojos muy azules".

Ilustrando la situación que por esa época se vivía en Chile con los males venéreos, tenemos un vigoroso artículo de Waldemar Coutts pidiendo terribles medidas de control. A raíz de un alza de estas enfermedades en el Apostadero Naval de Talcahuano, se había practicado en junio de 1930 "una inspección y examen obligatorio a más de 150 mujeres que trabajaban en restaurantes, casas de pensión, hoteles, etc," comprobando que las cifras eran todavía más altas que las oficiales. Coutts, por entonces Jefe Técnico de la Sección Higiene de la Dirección General de Sanidad, proponía "la absoluta necesidad de establecer la declaración, el tratamiento y el examen obligatorios de toda persona en estado de trasmitir un mal venéreo, aparte del castigo del delincuente venéreo consciente". Según Coutts, "el tratamiento obligatorio, hasta la completa curación del mal, es la base del éxito de toda campaña", agregando que "esta disposición pone al abrigo de la posibilidad que individuos infectados no soliciten curación para su mal de médicos o servicios especializados, y prefieran curarse por sí mismos". Y concluye proponiendo medidas terribles: "debe establecerse el castigo del delincuente venéreo consciente, hospitalizándolo forzadamente, a la vez que prohibiendo el tratamiento de estos males por charlatanes, el anuncio en los periódicos de drogas o medicamentos para curar 
estos males y su expendio en las farmacias sin receta de médico-cirujano"6. ¿Qué tal? ¡Cómo clamarían al cielo, con justa razón, los defensores de los human rights!

Por esos años, el IBCh ofrecía entre sus productos comerciales "Hemolisina para la reacción de Wassermann", pero no antígeno ${ }^{7}$. El desafío no era menor y Dussert lo acometió con entusiasmo y método durante más de una década, pero escasamente alcanzó a ensayar en el Wassermann su cardiolipina estandarizada, pues a poco andar el IBCh adoptaría el más sencillo Kahn. Dussert guardó el secreto de la fabricación del ahora llamado "antígeno de Kahn" como se hiciera con la fórmula de la Coca Cola, y sólo lo comunicó a su ayudante Mercedes Sentis, profesora de biología que asumió su fabricación ininterrumpida hasta la llegada del VDRL. En un par de ocasiones pretendimos que nos enseñaran el método misterioso, pero ni una ni otro accedieron, negándose redondamente.

Las primeras comunicaciones de Kahn sobre su reacción fueron hechas en $1922^{8,9}$. El 10 de octubre de 1923, en la asamblea del Public Health of Boston, secundado por Duemling realizó, ante un auditorio muy concurrido, cuarenta reacciones con sueros conocidos y cuidadosamente estudiados antes por Hinton, serólogo de la localidad. Cuenta Dussert: Los resultados fueron halagadores; el joven serólogo obtenía, en el mínimo de tiempo, resultados tan exactos y más sensibles que los obtenidos con las técnicas más delicadas. La reacción de Kahn hizo especial sensación en la Conferencia de Serología convocada por el Comité de Higiene de la Liga de las Naciones, donde sus resultados, del todo inesperados, le valieron la denominación de "Prueba Americana", tanto se identificaba la reacción misma con el espíritu del Nuevo Mundo. Iguales resultados sensacionales obtenía Kahn en Montevideo en $1930^{10}$.

En esos tiempos en que los médicos viajaban raramente, no como ahora en que algunos viven volando, el Profesor Dussert realizó dos viajes decisivos para la implantación del Kahn en Chile. El primero ocurrió en 1930 y fue para asistir al Tercer Congreso Mundial de Serología, como delegado del Gobierno de Chile, ocasión en que conoció a Reuben Kahn, con quien entablaría una larga y fructífera amistad. El segundo fue en 1941 al laboratorio de Kahn en la Universidad de Michigan, Ann Arbour, comisionado tanto por la Universidad de Chile, que no puso un peso, y el Ministerio de Salud, que asumió el costo.

Este segundo viaje permitió a Dussert estandarizar definitivamente la reacción, implantarla en el IBCh, fabricar y distribuir el antígeno por todo el país, incluso con venta directa a particulares en sus versiones "Standard" y "Presuntivo". En la parte afectiva, constituyó para el viajero un recuerdo imborrable, que relata así: El que escribe estas líneas recordará siempre con profundo cariño y emoción las múltiples pruebas de amistad que recibió de parte del Dr. Kahn y todos sus colaboradores. Para él, esa época por esta y otra circunstancia será siempre la más bella de su vida. Durante ella adquirió las más provechosas enseñanzas y forjó una amistad entre personas que hablan el mismo lenguaje cientifico, que tienen las mismas inquietudes y una misma finalidad en la vida, aunque los separen las distancias... En ese laboratorio Jefe y ayudantes palpitan al unisono para un mismo ideal: todos trabajan con una misma finalidad superior. Así es el laboratorio del Dr. Kahn. El que tiene la suerte de visitarlo y es conocedor del problema, queda de inmediato prendado de su jefe y admira su personal en general. Alli no se va en busca de una organización rígida para observar cómo un Jefe ha logrado ritmar mecánicamente el trabajo frío y rutinario de un laboratorio; no, allí se encuentra algo más que no lo puede dar la organización rígida, sino el valor moral y cientifico del Jefe: sólo así se explica esa atmósfera cálida y atractiva indispensable para el éxito de una empresa".

Un rumor no confirmado era que, en ese viaje, Dussert se trajo el espectacular Packard convertible del 39. Era un modelo Victoria color concho de vino, siempre cubierto de polvo, en que los sábados se venía desde su parcela en Quilicura, donde moraba los fines de semana. Una vez en la década de los sesentas subimos a este mastodonte: sentados adelante, parecía que íbamos a gran altura y apenas divisábamos, al final del infinito capó, una curiosa estatuilla representando a un cisne con el cuello inclinado y las alas desplegadas, como puede verse en la Enciclopedia Salvat ${ }^{11}$. En los días de semana se movilizaba, como buen francés, en un clásico Citroen 11 Léger negro, compra que su discípulo y mano derecha Eduardo Donoso había imitado, pero mientras la máquina del maestro funcionaba regularmente, la del pupilo fallaba de continuo, y no eran raros los atardeceres en que, codo a codo con el profesor, empujábamos la cacharra. Dussert era un hombre obeso y ventrudo, que se movía con lentitud y daba la impresión de blandura, pero empujando mostraba una fuerza notable y su prueba de fuego fue empujar nuestro elefantiásico cupé De Soto 48: creímos que iba a infartarse. Pese a su vigor, costaba imaginarlo subiendo escalas en los incendios que iba a apagar con su querida Pompe France, constituyendo esta riesgosa y filantrópica actividad una faceta inesperada de su carácter apacible y plácido. Según José Dalborgo, su sucesor en la Dirección del IBCh y su antítesis natural, era tan cómodo que le daba lata ir a comprar un auto nuevo, dicho al comentar nosotros la vetustez de sus dos vehículos.

La amistad con Reuben Kahn continuó hasta el fallecimiento de Eduardo Dussert, como lo muestra el singular hecho que el norteamericano autorizara al menos hasta 1959 la publicación de algunos artículos suyos en el modesto Boletín del IBCh que había sucedido a la 
original y más ambiciosa Revista ${ }^{12}$. Por entonces, Kahn estaba abocado de lleno al desarrollo de su tesis de la "reacción serológica universal" en que había convertido el test para la sífilis, definiendo su técnica como "un sistema múltiple de la reacción cuantitativa de precipitación, a diferentes concentraciones de $\mathrm{NaCl}$ ". En su libro "Reacción serológica universal en salud y enfermedad", que regalara en 1951 a su amigo Dussert "with high regard and best wishes" y que actualmente está en nuestras manos tras el remate de la extensa biblioteca de éste, Kahn expresaba que "todos los seres humanos y animales hasta ahora examinados con esta técnica han probado dar estas precipitaciones, de manera que estas reacciones aparentemente representan una manifestación biológica de naturaleza universal" 13

La reacción de Kahn, aunque más simple que la de Wassermann, tampoco era muy sencilla, ocupando una montonera de tubos. El antígeno seguía siendo un extracto alcohólico y desecado de corazón de buey (también servía el humano) al cual se le habían removido con éter las fracciones solubles. A éste se le agregaba colesterol, cuya función nunca estuvo muy clara, hasta una concentración final del 0,6\%. Luego el antígeno se estandarizaba hasta descubrir la menor concentración salina que, al agregarle 1 $\mathrm{mL}$ de antígeno, produjera agregados capaces de completa dispersión al exceder dicha concentración, que usualmente estaba entre 1 y $1,5 \mathrm{~mL}$ por cada $\mathrm{mL}$ de antígeno... ¿Clarísimo, verdad? La serie comprendía 3 tubos con distintos volúmenes de antígeno: $0,05 \mathrm{~mL}, 0,025 \mathrm{~mL}$ y $0,0125 \mathrm{~mL}$, agregándose a cada uno $0,15 \mathrm{~mL}$ del suero inactivado del paciente, sacudiéndolos a mano durante 10 segundos. Luego se adicionaba $1 \mathrm{~mL}$ de solución salina al primer tubo y $0,5 \mathrm{~mL}$ a los dos siguientes, metiéndolos todos a un agitador mecánico por 3 minutos.

La lectura del Kahn también tenía, como el Wassermann, un componente subjetivo, existiendo seis posibilidades de resultados: cuatro positivas, con partículas fácilmente visibles, que el lector clasificaba, según su número, tamaño y visibilidad, de 1 a 4; una quinta dudosa, con partículas muy finas, apenas visibles; y una sexta y última negativa, opalescente y sin partículas.

El test presuntivo se hacía con un antígeno más sensible y servía de escrutinio o screening, como dicen los american boys, denominación burlona que daba Dussert a quienes, como nosotros, seguíamos a los norteamericanos, ya más adelantados en microbiología que los franceses:

-Ustedes - nos decía - que hablan de esa payasada... ¿cómo se llama? ¡Ah, el ARN mensajero! ¡American boys!

En 1951, cuando ya la técnica estaba más que estandarizada y el IBCh vendía el antígeno urbi et orbi, la doctora Araceli Amo se hizo cargo de ella, llegando a desarrollar un ojo infalible para su lectura. En las tardes, fumando y charlando incesantemente con su colega y amiga Celia Aguilar en la Sección Diagnóstico, se hacía traer las muchas gradillas con los tubitos de Kahn y los leía sin vacilación y sin dejar de charlar.

El Wassermann no fue derrotado fácilmente: se resistió a morir y coexistió con el Kahn muchos años, amparado por los médicos más antiguos, que desconfiaban de los cambios, no siendo infrecuente que se solicitaran al paciente los dos tests al mismo tiempo. Existió en los primeros años la impresión que, en manos poco experimentadas, el Kahn no era tan fiel como en manos de su autor ${ }^{14}$. Con el tiempo y a medida que se divulgaba y estandarizaba en todas partes, el Kahn terminó por imponerse, aunque no faltaran investigadores como Kolmer o Kline, por dar algunos ejemplos, que intentaron mejorar una y otra reacciones.

Si el Kahn terminó con el Wassermann, el VDRL terminaría con ambos. En realidad, el principio de las tres reacciones fue siempre el mismo, esto es, el empleo de cardiolipina como antígeno, y sólo fue cambiando su "purificación", por así decirlo, a fin de disminuir los falsos positivos, que se producían con una serie de patologías frecuentes y ominosas, como tuberculosis, lepra, malaria y varias más, pues no sin razón hablaba Kahn de una reacción "universal". Todo extracto orgánico, decía Harrison en su extenso texto sobre la sífilis ${ }^{14}$, es un producto altamente complejo, con tres propiedades: antigénico, anticomplementario y hemolitico, la primera deseable y las otras dos indeseables, de modo que varias modificaciones se fueron haciendo para aumentar la primera y disminuir las otras, hasta que Kolmer en 1928 lo consiguió haciendo la extracción con éter... Harrison no alcanzó a ver el final de esta mejoría continua, que fue el VDRL.

El VDRL, sigla que recuerda la institución donde fue desarrollado, el Venereal Diseases Research Laboratory, databa de 1946-48, cuando en el IBCh recién empezaba a reinar el Kahn ${ }^{15,16}$. Usaba el mismo antígeno cardiolipina, con modificaciones menores, y se realizaba en lámina, tras agitación en un instrumento muy sencillo, existiendo las variedades cualitativa, sin diluir, y cuantitativa, con cuatro o más diluciones.

Aun siendo una técnica tan simple, el sabio Dussert estimó que alguien debía ir a Estados Unidos a aprenderla in situ. No era necesario que viajara un médico, en este caso Araceli Amo, sino alguno de los técnicos que fuera luego a realizarla con sus manos. Ahora bien, los tecnólogos médicos recién estaban apareciendo en el Instituto, y no había ninguno en el Laboratorio de Serología, por lo cual se escogió la única auxiliar con conocimientos de inglés, Olga Tolstov, de nacionalidad rusa, quien trabajaba en bacteriología de alimentos. Ella viajó al gran país del norte y trajo de vuelta el VDRL, que enseñó a sus compañeras de Serología, y a poco andar el nuevo test desbancó para siempre al Kahn. Faltaba, eso 
sí, divulgarlo e implementarlo en el resto del país, para lo cual era preciso volver al viejo sueño de una red de laboratorios, comandada y normada por el IBCh. Pero ocurrió un imprevisto y Dussert no alcanzó a ver cumplido tal sueño: fue destituido en 1967.

A Eduardo Dussert nunca le atrajo la idea de ser Director y si en 1962 accedió a ocupar el cargo, fue por su sentido del deber, al ver que no había entre sus supuestos pares ninguno capacitado, pero siempre se sintió sólo “de paso", a tal punto que en la vasta sala de la Dirección se sentó siempre en la mesa redonda de Consejo Técnico, y nunca ocupó el escritorio que había sido de Eugenio Suárez, cuyos cajones encontraríamos más tarde repletos con los papeles de este mítico personaje, vaciándolos sin compasión y casi provocando al respetuoso Dussert un ataque de apoplejía.

En un principio las cosas anduvieron bien, pero el profesor, un científico e intelectual de primera línea, por una parte desconocía los principios de la administración y, por otra, carecía de liderazgo. El descontento entre los institutanos fue creciendo, sintiendo que la institución se había estancado, en lo cual tenían razón: nadie era enviado a perfeccionarse en centros extranjeros, existiendo para ello excelentes contactos con el Instituto Pasteur de París, por nombrar alguno, y puntos vitales del IBCh se fueron quedando atrás, como la planta de penicilina y la producción de vacunas. A todas nuestras peticiones en ese sentido, el profesor Dussert respondía con evasivas y hasta con respuestas ofensivas para nuestra capacidad.

$\mathrm{Al}$ interior del IBCh existía un grupo con ansias innovadoras, autodenominado jocosamente los pumas, que no era una asociación formal, ni secreta ni organizada, sino profesionales que conversaban en los pasillos y en los patios. Al exterior tenían el apoyo del José Manuel Borgoño, médico delegado por la Dirección General del Servicio Nacional de Salud al Consejo Técnico del IBCh, en cuyas reuniones fustigaba con frecuencia la inacción del profesor, espoleado por los exasperados reclamos de Pedro Mikacic, el Director de la Central de Abastecimiento, harto de los incumplimientos en las entregas de los sueros, vacunas y antibióticos. El resultado no podía demorar y Dussert fue depuesto en 1967, asumiendo en su lugar Ernesto Pearson, infectólogo de la cátedra del Profesor Kraljevic, que desde hacía años trabajaba en el Departamento de Virología.

Al profesor Dussert se le mantuvo en el IBCh, abocado a la formación de un Centro de Microbiología, anticipo de la famosa red. Desde allí pensó desarrollar el VDRL en los laboratorios nacionales, pero no alcanzó a llevar a cabo esta idea, mérito que correspondería a Mario Miranda, quien asumió la Dirección del IBCh en 1969. Miranda partió por el principio, creando un Departamento de Adiestramiento, encargado de realizar cursos en el Instituto y en provincia para difundir y estandarizar todas las técnicas microbiológicas. En tal Departamento, con Victoria Beresi y Rodrigo Cassorla G. nos correspondió en 1970 hacer un curso de dos semanas enseñando VDRL a tecnólogos médicos y auxiliares de laboratorio de todo el país.

Los noveles profesores nunca habíamos visto ni realizado una reacción de VDRL hasta una semana antes del inicio del curso. El Departamento de Adiestramiento era resistido por todo el Departamento de Laboratorios, cuyos profesionales ni entendieron ni se esforzaron por entender nuestra misión, y Araceli Amo no hacía excepción, pero era toda una dama $y$, sin manifestar su molestia, nos dio las facilidades para aprender el test en su laboratorio. Quedamos boquiabiertos al ver tanto ruido por tan pocas nueces: la famosa reacción era de una facilidad asombrosa y la aprendimos en un rato. Todo el secreto del éxito, descubrió Cassorla, estribaba en obtener una gota del volumen adecuado, para la cual hizo una modificación, mínima y no publicada, a la inclinación de la aguja, gracias a la cual nos lucimos antes nuestros alumnos y le contribuimos para darle al Kahn la puñalada mortal.

La enseñanza del VDRL continuó luego con estadías de laboratoristas en la Sección Serología, a cargo de Liliana Urra, quien sucediera a Araceli Amo en 1971. La red de laboratorios llegó a ser una realidad al transformarse el Instituto Bacteriológico en Instituto de Salud Pública en 1980, y dentro de ella la red de serología de la sífilis fue una de las primeras y más activas, entregando antígenos, sueros controles y realizando evaluaciones periódicas a los laboratorios de su red.

\section{El tiempo ha pasado y no en vano \\ Las cosas de antaño se fueron \\ Nosotros quedamos atrás: \\ Quizás resistamos al tiempo ${ }^{17}$.}

Rudolph Kraus murió en 1932 y no alcanzó a ver el fin del Wassermann y el reinado del Kahn; Eduardo Dussert murió en 1972 sin sufrir la extinción del Kahn y el advenimiento del VDRL: los grandes protagonistas de esta historia no resistieron al tiempo.

\section{Resumen}

El autor recuerda, a veces en una muy personal y coloquial forma, la adopción por el Instituto Bacteriológico de las tres reacciones para el diagnóstico presuntivo de la sífilis que empleaban antígenos no treponémicos: Wassermann, Kahn y VDRL. Las señeras figuras de algunos de los gestores de estos cambios, como Rudolf Kraus, Eduardo Dusssert y Reuben Kahn son recreadas con las palabras de testigos de primera mano. 


\section{Referencias bibliográficas}

1.- Wassermann A, Neisser A, Bruck C. Eine serodiagnostische Reaktion bei Syphilis. Deutsch Med Wochensch Berlin, 1906, 32: 745-6.

2.- Marie A, Levaditi C. Ann Inst Pasteur 1907; 21: 138.

3.- Laval R, E. Tifus exantemático en Chile. Rev Chilena Infectol Edición Aniversario 2003; 56.

4.- Romanangel. Fidel Cornejo y Cía. Editorial Cultura, Santiago 1935.

5.- Kraus R. August von Wassermann 1865-1925. Seuchenbekämpfung und experimentelle Therapie 1925, 11: 104-1069.

6.- Coutts W E. La necesidad de establecer medidas legales para la lucha contra los males venéreos. Revista del Instituto Bacteriológico de Chile. Boletín de la Sociedad Chilena de Microbiología e Higiene. 1930, 1 (4): 33-5.

7.- Revista del Instituto Bacteriológico de Chile 1930; 1 (4): contratapa.

8.- Kahn R L. Effect of dilution on the precipitation reaction for syphilis proponed by the author. Proc Soc Exper Biol Med 1922; 19: 194

9.- Kahn R L. A simple quantitative precipitation reaction for syphilis. Arch Dermatol Syphil 1922; 5: 734.

10.- Dussert E. Veinticinco años de la reacción de Kahn. Boletín del Instituto Bacteriológico de Chile 1948; V (2): 73-5.

11.- Packard. Enciclopedia Salvat del Automóvil. Salvat S.A. de Ediciones, Pamplona 1979; 8: 219-26.

12.- Kahn R L. Effect of irradiation on some aspects of tissue immunity. Boletín del Instituto Bacteriológico de Chile 1959; 58-9.

13.- Kahn R L. Universal serologic reaction in health and disease. The Commonwealth Fund, New York 1951.

14.- Harrison L W, Bulloch W, Hindle B. Syphilis. En: Medical Research Council. A system of bacteriology in relation to medicine. His Majesty's Stationery Office, London 1931; vol VIII: 252-4

15.- Harris A, Rosenberg A A, Riedel L M. A microfloculation test for syphilis using cardiolipin antigen. J Vener Dis Inform 1946; 27: 169-74.

16.- Harris A, Rosenberg A A, Vechio E R. The VDRL slide floculation test: A supplementary report. J Vener Dis Inform 1948; 29: 72-5.

17.- Ledermann F R. Gusano. Centro de Estudios Humanistas Julio Prado, Santiago1962. 